\title{
Los enjuagatorios bucales en tiempos de Covid-19.
}

\section{Mouthrinses in Covid-19`s era}

\author{
1. Departamento de Odontología Restauradora, \\ Facultad de Odontología Universidad de Chile. \\ Chile.
}

${ }^{*}$ Correspondencia a: M.Consuelo Fresno | Dirección: Olivos 943, Independencia, Santiago Chile | E-mail: mcfresno@odontologia.uchile.cl

Trabajo recibido 09/03/2021

Trabajo revisado 13/03/2021

Aprobado para su publicación 17/03/2021

\section{María Consuelo Fresno ${ }^{1 *}$}

Con la irrupción en diciembre 2019 del virus SARS-CoV-2 todos los aspectos de nuestra vida se han visto profundamente afectados y al impactante número de pérdidas de vidas y las consecuencias sanitarias, se suman las repercusiones económicas. Sin embargo, quizás sea pronto para medir el alcance sociocultural de esta pandemia.

Desde el punto de vista de nuestra profesión, por indicación de las autoridades sanitarias, las atenciones odontológicas quedaron relegadas durante muchos meses a las urgencias, debido al desconocimiento general que se tenía del manejo de esta inédita situación de salud pública.

A más de un año del comienzo de esta crisis la población general y los profesionales de la salud entienden la forma de transmisión del virus y la importancia de tomar las precauciones para evitar contagios.

Diferentes estudios han demostrado que durante la atención dental existe una producción de aerosoles cargados de microorganismos ${ }^{(1,2)}$. Por este motivo, y para evitar riesgos los odontólogos hemos utilizado y seguido todas las medidas de bioseguridad necesarias para brindar una atención segura a los pacientes, así como salvaguardar las condiciones de trabajo al personal de colaboración. Es así que desde hace mas de 4 décadas, en nuestro trabajo cotidiano, utilizamos todos los elementos de protección para evitar el contagio de enfermedades virales como SIDA, hepatitis B, herpes, influenza y ahora el SARS-CoV- 2 . Algunos de estos protocolos incluyen el uso y eliminación adecuado de elementos de protección personal (EPP), la esterilización del instrumental y materiales de trabajo, la desinfección de las áreas clínicas y de uso común, la regulación del tránsito de pacientes y personal de clínica y además la eliminación y manejo de material biológico, entre otros ${ }^{(3,4)}$.

El mantenimiento y/o modificación de estas medidas requieren de una constante actualización de la información y un continuo análisis crítico de la evidencia.

Bajo este contexto, durante el último año diferentes autores han señalado que la cavidad bucal podría jugar un rol importante en la replicación y propagación de SARS-CoV-2 ${ }^{(5)}$ y, por tanto, los enjuagues bucales, potencialmente, podrían reducir la carga viral en la saliva de pacientes COVID positivos, de esta manera se podría minimizar el riesgo de transmisión del virus SARS-CoV-2. Igualmente su uso, previo a la atención odontológica, permitiría mantener un ambiente seguro en el interior de la consulta, protegiendo al odontólogo y al personal de la clínica, permitiendo, retomar definitivamente, en forma responsable y segura, la necesaria y urgente atención odontológica en todos los contextos (servicios públicos, privados y docentes) y dar solución a los problemas de salud bucal, que se han profundizado durante este complejo escenario que vivimos.

En la actualidad, hay pocos estudios publicados que reporten la eficacia de los enjuagues bucales antibacterianos contra el SARS-CoV-2, pero algunos de ellos pueden darnos luz acerca de su utilidad en este contexto. Con la literatura disponible se puede afirmar que:

1. Algunas asociaciones dentales se han hecho eco de la indicación que recomienda la realización de un enjuague bucal con peróxido de hidrógeno al $1 \%$, previo a los procedimientos odontológicos realizados por los profesionales. El objetivo es disminuir la carga viral de SARS-CoV-2 en saliva, en el caso de que el paciente se encuentre infectado, de este modo se disminuiría también su presencia en los aerosoles producidos que diseminen el virus. Sin embargo, en una revisión reciente, Ortega et $a^{\left({ }^{(6)}\right.}$ concluyen que, se debería revisar su indicación ya que existe falta de evidencia científica que respalde cualquier actividad viricida del enjuague bucal de peróxido de hidrógeno y además es conocido que esta molécula carece de sustantividad. Por otra parte, los estudios realizados, in vitro, muestran que su potencial viricida está muy por debajo de otros elementos contenidos en algunas fórmulas de enjuagues bucales presentes en el mercado ${ }^{(7)}$.

2. A la fecha, los estudios in vitro demuestran una baja efectividad de los enjuagues bucales que contienen digluconato de clorhexidona $(\mathrm{CHX})$, etanol o aceites esenciales en las concentraciones habituales de uso $(8,9,10,11)$.

3. El cloruro de cetilpiridinio (CCP), es un compuesto de amonio cuaternario presente en varios enjuagues bucales y aerosoles para el aliento. Posee una probada actividad antiséptica y antimicrobiana, y se ha demostrado in vitro, que reduce mil veces la infectividad del SARS-CoV-2 al inhibir la fusión del virus con las células diana y además tendría un efecto mantenido en la reducción del nivel salival de SARS-CoV-2 en pacientes con COVID-19 $(8,9,10,12,13)$.

4. Los enjuagues bucales que contienen Povidona lodada (PI) demostraron también ser efectivos, in vitro e in vivo, en la disminución mantenida de la carga viral(10).

Por lo descrito anteriormente, se puede señalar que los enjuagues bucales que contienen CCP o PI podrían representar una medida efectiva para reducir la carga viral de SARSCoV-2 en saliva. Esto ayudaría a reducir la transmisión viral de las personas infectadas, siendo además una estrategia antiviral económica y accesible a nivel transversal para ser 
implementada en todo el mundo. Así mismo, en el contexto médico y odontológico sumar a las medidas de bioseguridad ya conocidas como son: utilizar equipo de protección personal adecuado, hacer odontología a cuatro manos, usar si es posible succión de alta evacuación y aislación absoluta con diques de goma; el uso de los enjugues bucales para disminuir el contenido viral de los aerosoles producidos durante la atención en la clínica parece ser una buena propuesta.

Sin embargo por ser muy recientes, no se han publicado aún los resultados de los diferentes estudios clínicos que se encuentran en desarrollo(14) y así incluir a los enjuagues bucales a las diferentes indicaciones generales habituales como son: el distanciamiento social, uso de mascarilla, lavado frecuente de las manos o la misma vacunación.

\section{Bibliografía}

1. Ge ZY, Yang LM, Xia JJ. Possible aerosol transmission of COVID-19 and special precautions in dentistry. J Zhejiang Univ Sci B. 2020; 21(5):361-8. doi: 10.1631/jzus. B2010010.

2. Peng X, Xu X, Li Y, Cheng L, Zhou X, Ren B. Transmission routes of 2019-nCoV and controls in dental practice. Int J Oral Sci. 2020;12:9. doi 10.1038/s41368-0200075-9

3. Melo P, Barbosa JM, Jardim L, Carrilho E, Portugal J. Covid-19 management in clinical dental care. Part I: Epidemiology, public health implications, and risk assessmentint. Dent J. 2021 Feb 10. Epub ahead of print. doi: 10.1016/j.identj.2021.01. 4. Kamran A, Mahwish R. Coronavirus disease 2019 (COVID-19): challenges and management of aerosol-generating procedures in dentistry. Evid Based Dent. 2020; 21(2): 44-5. doi: 10.1038/s41432-020-0088-4

5. Baghizadeh M. Oral saliva and COVID-19. Review. Oral Oncol. 2020; 108.104821 https://doi.org/10.1016/j.oraloncology.2020.104821

6. Ortega KL, Rech BO, El Haje GLC, Gallo CB, Perez-Sayáns M, Braz-Silva OH. Do hydrogen peroxide mouthwashes have a virucidal effect? A systematic review. J Hosp Inf. 2020;106(4)657-62. https://doi.org/10.1016/j.jhin.2020.10.003

7. Meyers C, Robison R, Milici J, Alam S, Quillen D, Goldenberg D, et al. Lowering the transmission and spread of human coronavirus. J Med Virol. 2021:93:1605-12. doi: $10.1002 / j m v .26514$

8. Green A, Roberts G, Tobery T, Vincent C, Barili M, Jones C. In vitro assessment of the virucidal activity of four mouthwashes containing Cetylpyridinium Chloride, ethanol, zinc and a mix of enzyme and proteins against a human coronavirus. bioRxiv. 2020: https://doi.org/10.1101/2020.10.28.359257;
9. Statkute E, Rubina A, O'Donnell V, Thomas DW, Stanton RJ. Brief Report: The virucidal efficacy or oral rinse components against SARS-COV-2 in vitro. bioRxiv. 2020. https://doi.org/10.1101/2020.11.13.381079

10. Seneviratne CJ, Balan P, Ko KKK, Udawatte NS, Lai D, Ng DHL, et al. Efficacy of commercial mouth-rinses on SARS-CoV-2 viral load in saliva: randomized control trial in Singapore. medRxiv. 2020. doi.org/10.1101/202

11. Meister TL, Brüggemann Y, Todt D, Conzelmann C, Müller JA, Groß R, et al. Virucidal efficacy of different oral rinses against Severe Acute Respiratory Syndrome Coronavirus 2. J Infect Dis. 2020 Sep 14;222(8):1289-92. doi: 10.1093/infdis/ jiaa471.

12. Muñoz-Basagoiti J, Perez-Zsolt D, León R, Blanc V, Gispert J, Clotet B, et al Cetylpyridinium chloride-containing mouthwashes reduce in vitro SARS-CoV- 2 infectivity. bioRxiv. 2020; https://doi.org/10.1101/2020.12.21.423779

13. Komine A, Yamaguchi E, Okamoto N, Yamamoto K. Virucidal activity of oral care products against SARS-CoV-2 in vitro. J Oral Maxillofac Surg Med Pathol. $2021 \mathrm{Feb}$ 22. Epub ahead of print. doi: 10.1016/j.ajoms.2021.02.002

14. Burton MJ, Clarkson JE, Goulao B, Glenny A-M, McBain AJ, Schilder, et al. Antimicrobial mouthwashes (gargling) and nasal sprays administered to patients with suspected or confirmed COVID19 infection to improve patient outcomes and to protect healthcare workers treating them. Cochrane Database of Sys Rev. 2020, 2020 Sep 16;9:CD013627. doi: 10.1002/14651858.CD013627.pub2. [Accessed $07 / 03 / 2021]$ 